\title{
OBSERVATIONS ON A GYNOCHROMATIC (?) MALE OF THE DRAGONFLY, RHODOTHEMIS RUFA (RAMBUR, 1842) (ODONATA: LIBELLULIDAE)
}

\author{
Raymond J. Andrew
}

ISSN 0974-7907 (Online) ISSN 0974-7893 (Print)

Post Graduate Department of Zoology, Hislop College, Nagpur, Maharashtra 440001, India rajuandrew@yahoo.com

Abstract: The dragonfly Rhodothemis rufa exhibits a conspicuous sexual dimorphism in its body colour. The mature male is characterized by the homogenous striking brilliant red body while the mature female is dull brown with a prominent mid-dorsal light yellow streak running from the top of the head through the thorax and down to the fifth segment of the abdomen. The sexes can easily be identified from quite a long distance. On 7 November 2012, we observed the unusual sight of a female Rhodothemis rufa chasing another female and forming a tandem link which was followed by copulation. This peculiar reproductive behavior instigated us to net the specimen. On inspection we found that although it appeared a female, it had well developed external male genitalia in the form of the secondary copulatory apparatus on the venter of the second and third abdomen, a pair of coxites on the ninth abdominal tergum and an additional infra anal appendage at the terminal tip of the abdomen. The testes contained a large number of lobules filled with mature spermatozoa, and the vasa differentia also contained mature sperms. The sperm sac was filled with sperms embedded in seminal fluid. Observations indicate that this could be a rare case of a gynochromatic male of Rhodothemis rufa which has retained the colour patterning of the female even after sexual maturity and concomitantly exhibiting active sexual behaviour, although the case of it being a subadult male which has yet to attain its typical red coloration cannot be ruled out.

Keywords: Colour change, dragonfly, gynochromatic, Rhodothemis rufa.
In the Libellulidae, males are mostly brightly coloured or acquire striking colour patterns as they mature. Colours and patterns on the wings and body play an important role in territoriality and courtship behavior of these insects (Subramanian 2005; Andrew et al. 2008). Reports of gynochromatic males and androchromatic females in the Libellulidae are rare (Corbet 1999; Andrew 2013).

The Common Red Skimmer Rhodothemis rufa is a monotypic species, a rather large Libellulid, commonly found hawking around weedy tanks or settled on herbage around the water body. This species exhibits a high degree of sexual dimorphism. The mature male (Image 1 b) is characterized by the homogenous bright red colour which closely resembles that of Crocothemis servilia, C. erythrea and the red species of Orthetrum. The female is more brown (Image 1a). See Table 1 for the differences. Freshly emerged individuals of both sexes have the female pattern of colouration. As the male matures, it gradually develops its characteristic red
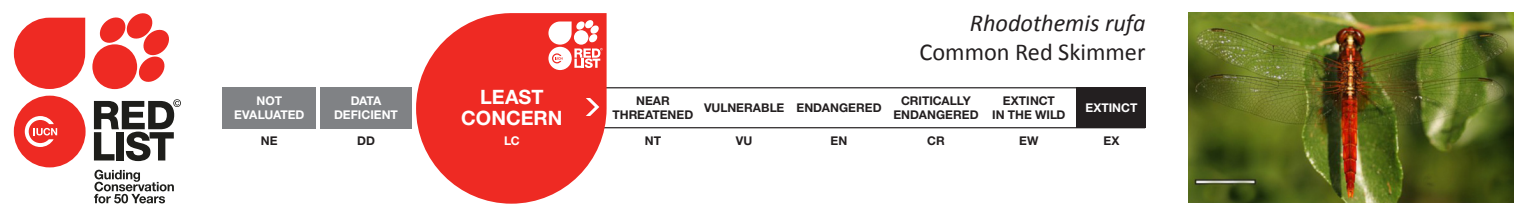

DOI: http://dx.doi.org/10.11609/JoTT.03868.7007-10

Editor: Nancy van der Poorten, Toronto, Canada.

Date of publication: 26 March 2015 (online \& print)

Manuscript details: Ms \# 03868 | Received 24 November 2013 | Final received 17 January 2015 | Finally accepted 04 March 2015

Citation: Andrew, R.J. (2015). Observations on a gynochromatic (?) male of the dragonfly, Rhodothemis rufa (Rambur, 1842) (Odonata: Libellulidae). Journal of Threatened Taxa 7(3): 7007-7010; http://dx.doi.org/10.11609/JoTT.03868.7007-10

Copyright: (C) Andrew 2015. Creative Commons Attribution 4.0 International License. JoTT allows unrestricted use of this article in any medium, reproduction and distribution by providing adequate credit to the authors and the source of publication.

Funding: Self funded.

Competing Interest: The author declares no competing interests.

Acknowledgements: I thank the Principal Dr. Mrs. D. R. Christian and Management of Hislop College, Nagpur for providing laboratory facilities. I am grateful to Dr. K.A. Subramanian of ZSI, Kolkata and David Raju for the photograph of male and female $R$. rufa. The exhaustively scrutiny and correction of the manuscript by the refree (Nancy van der Poorten of Toronto, Canada) is sincerely acknowledged. 

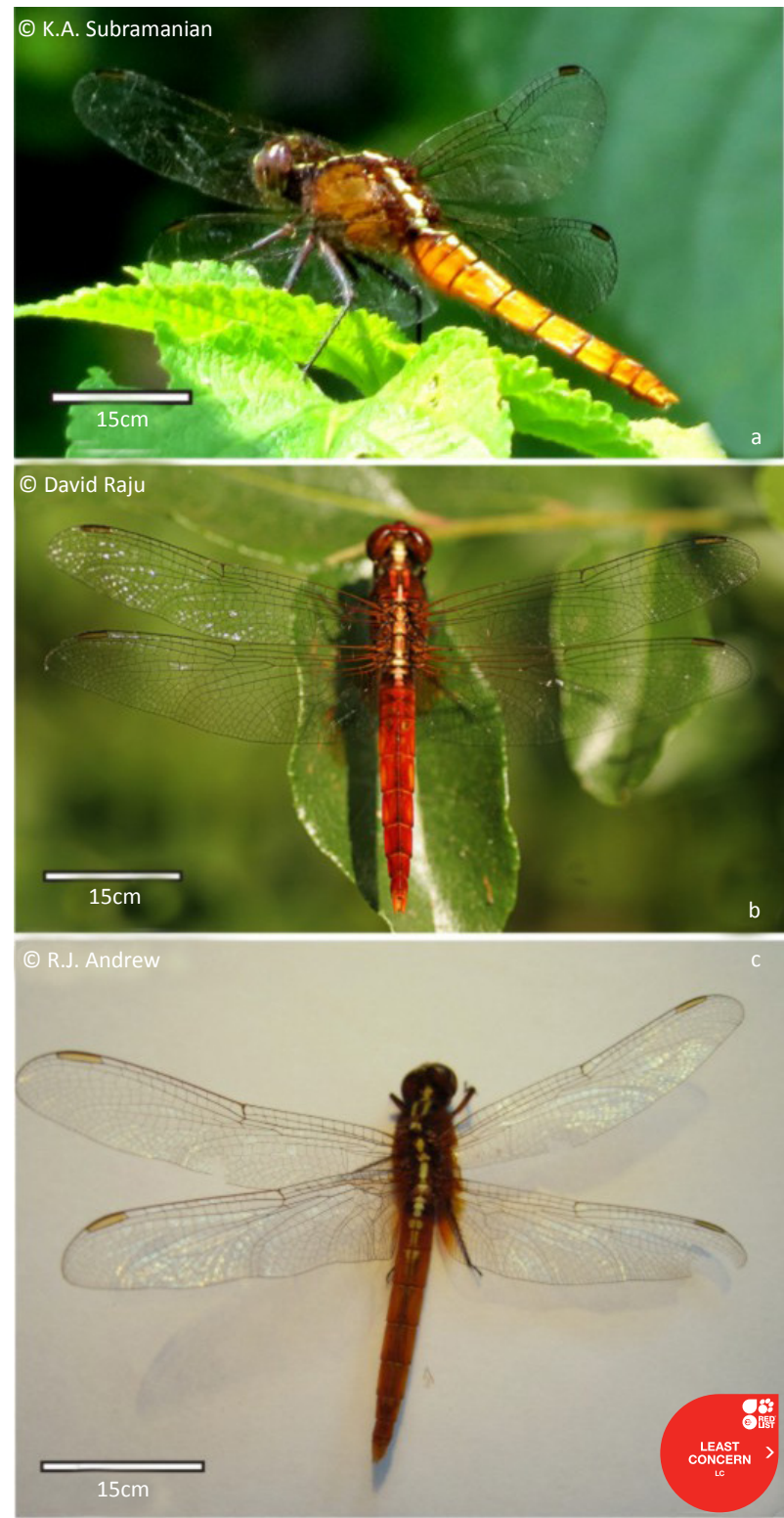

Image 1. Rhodothemis rufa.

a - Mature female; b - Mature male; c - Collected male.

colour so that during courtship, it is well equipped with its vibrant red colour patterning.

\section{Observation ANd Methods}

On 7 November 2012, we observed a female Rhodothemis rufa chasing another female and it soon formed a tandem linkage which was followed by copulation. We netted the specimen (Image 1c) and were surprised to observe that although it looked like a female (Image 1a), it bore the secondary copulatory apparatus on the venter of the second and third segments of the abdomen, a pair of coxites on the ninth abdominal tergum and also contained an additional infra
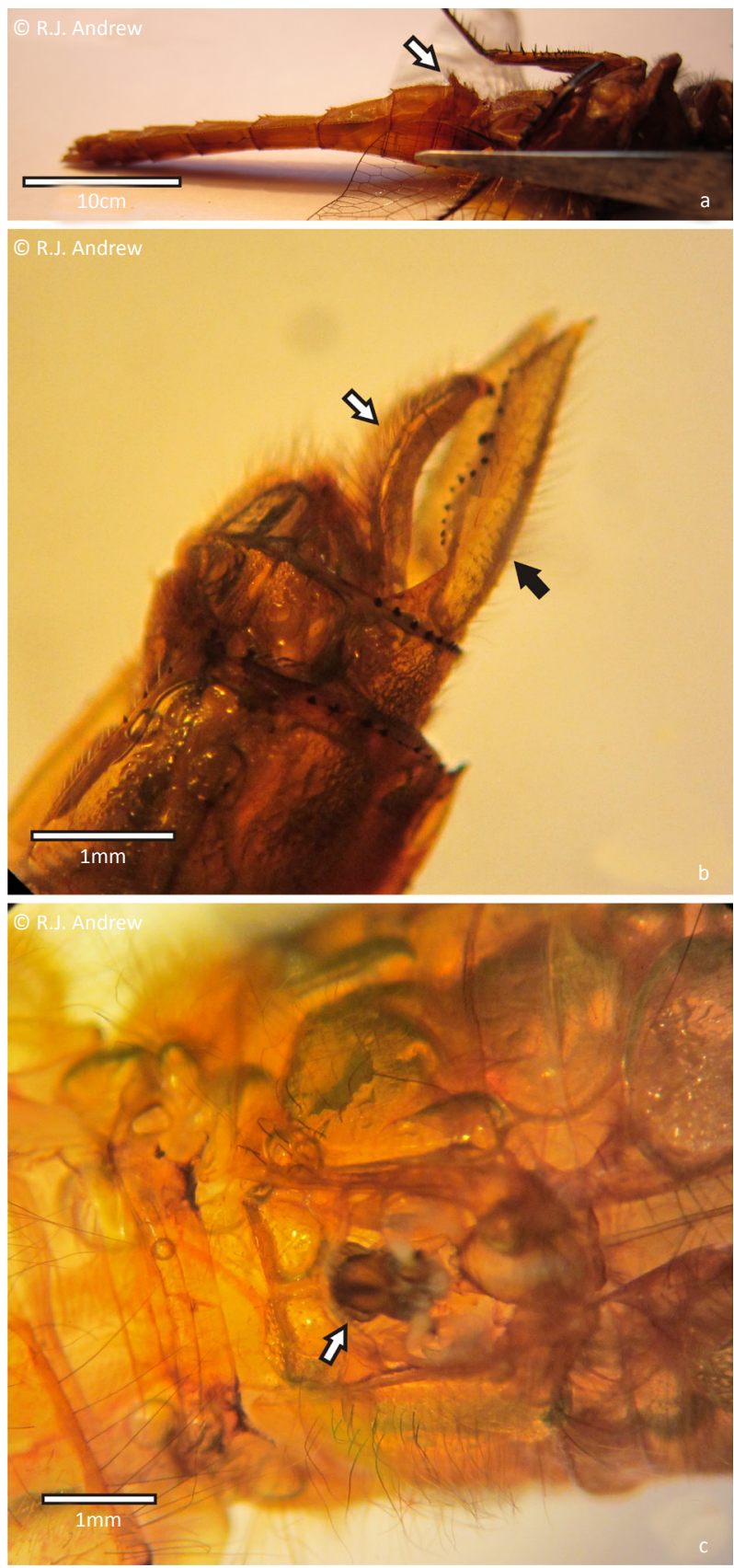

Image 2. Details of the collected Rhodothemis rufa male.

a - Male secondary copulatory apparatus (arrow) located at the anterior end of the abdomen; $\mathbf{b}$ - Supra anal (black arrow) and infra anal (white arrow) appendages; c - Penis of the secondary copulatory apparatus (arrow).

anal appendage at the terminal tip of the abdomen, all male specific characteristics.

The specimen was examined under the stereoscan microscope and the internal reproductive organs were dissected, fixed in Bouins fluid, embedded in paraffin wax at $62^{\circ} \mathrm{C}$, sectioned by a rocking microtome, stained with Eosine-Haematoxyline and observed under the research microscope. 


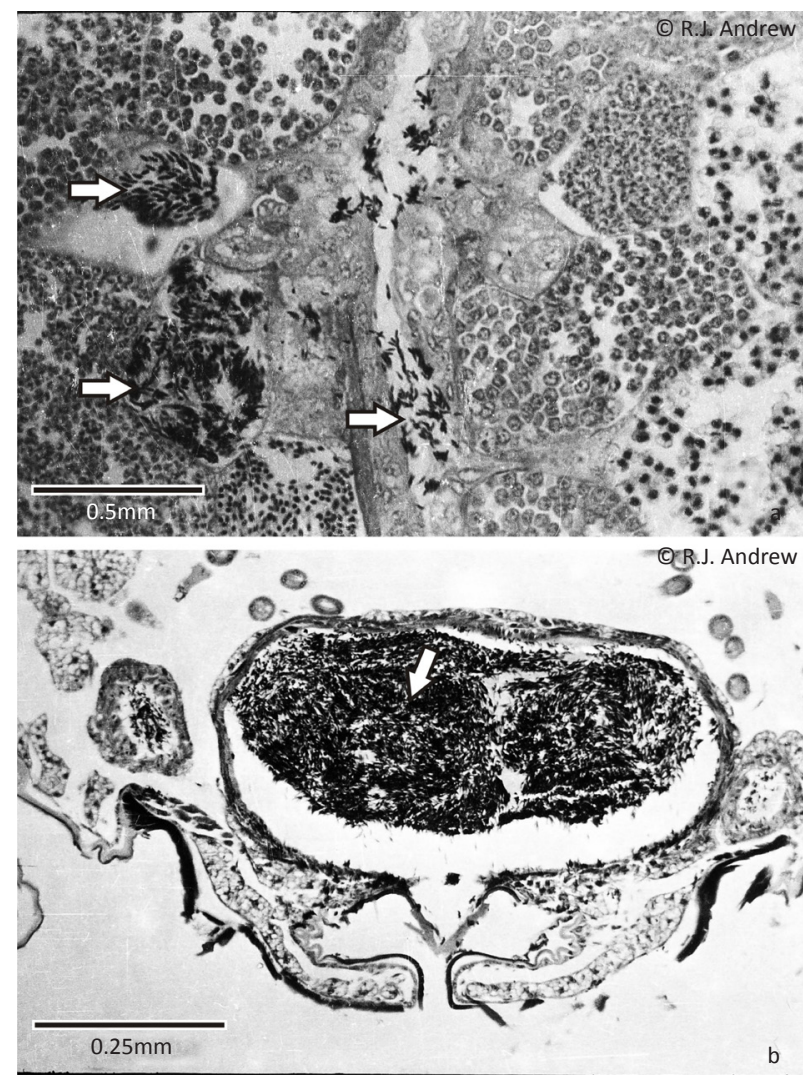

Image 3. a - Section of the testis of the collected Rhodothemis rufa showing lobules and vasa differentia filled with mature spermatozoa (arrows); b - Section of the sperm sac filled with mature spermatozoa (arrow).

Histological observation revealed that the testes contained a large number of lobules filled with mature spermatozoa (Image 3a), and the vasa differentia also contained mature sperms. The sperm sac was filled with sperms embedded in seminal fluid (Image 3b).

The collection site was the western border of Telenkhedi Pond of Nagpur City. This section of the pond is covered with submerged, floating and marginal aquatic flora. A detailed account of this site has been described by Andrew (2013).

\section{Discussion}

The teneral and sub-adult male of several species of Libellulid dragonflies (for example Potamarcha obscura, Orthetrum brunneum brunneum, $O$. chrysostigma Iuzonicum, O. glaucum, Brachydiplax sobrina, Trithemis festiva and Rhodothemis rufa) resemble the female. The specific characteristic male colour patterning, which is different from that of the female, develops as the male matures (Fraser 1936). In most of such cases the female is always comparatively dull in colour patterning where as the mature male develops a striking brilliant red colour. Sexual maturation and the rate of colour change have been shown in some species to take place in response to environmental cues and to be under the control of the juvenile hormone (Hinnekint 1987; Corbet 1999). According to McVey (1985), food intake and air-temperature also play an important role in colour change in male Erythemis simplicicollis dragonflies. In the subadult and teneral phases of the odonates Somatochlora arctica (Midttun 1974) and Leucorrhinia dubia (Pajunen 1962), the testis does not contain developed spermatozoa and the seminal vesicle (sperm sac) is empty and devoid of spermatozoa. However, mature and active spermatozoa are found in day-old Enallagma cynthigerum and Ishnura elegans (Corbet 1999). In the $R$. rufa specimen the testes contained a large number of lobules filled with mature spermatozoa, and the vasa differentia/seminal vesicle also contained mature sperms. The sperm sac was filled with sperms embedded in seminal fluid. Although the presence of mature sperm is correlated with the mature colour change in Argia moesta and Lestes sponsa (Uéda 1989), in Leucorrhinia dubia, the testes mature four to five days after emergence and the colour develops much later by the $10^{\text {th }}$ day while sexual behavior is expressed after the $13^{\text {th }}$ day (Pajunen 1962). In Megaloprepus coerulatus, the adult colour develops within a day of emergence but the male requires three to four weeks to become sexually mature (Fincke 1992). Thus it becomes very tricky to define a male gynochromatic in Odonata. On the one hand the collected specimen of Rhodothemis rufa appears to be a subadult who has reached testicular maturity but has yet to develop adult colour. On the other hand three factors in the present observation, firstly the gynochromatic colour of the male, secondly the presence of mature spermatozoa in testis and sperm sac and third (and probably most significant) the active reproductive behavior of the individual occurring at the same time tilt the scale towards the specimen being a gynochromatic male.

\section{CONCLUSIONS}

On thorough examination of the external male genitalia, state of internal reproductive organs and comparison with the typical male and female of Rhodothemis rufa (Table 1), the collected specimen could be a gynochromatic male of Rhodothemis rufa or a sub adult lacking "mature colouration". Although it is very tricky to define a male gynochromatic in Odonata, the following three aspects (female colour pattern, mature testis and spermatozoa in sperm sac and active reproductive behavior) occurring concomitantly 
Table 1. A comparative account of the colour patterning between normal mature male, normal mature female and the collected (gynochromatic?) male of Rhodothemis rufa (Image 1c).

\begin{tabular}{|c|c|c|c|}
\hline Region & Normal mature male & Normal mature female & Collected (gynochromatic?) male \\
\hline \multicolumn{4}{|l|}{ Head } \\
\hline Labium & Reddish-brown & Blackish-brown & Brown \\
\hline Labrum & Reddish-ochreous & Blackish-brown & Brown \\
\hline Anteclypeus & Reddish-ochreous & Blackish-brown & Brown \\
\hline Postclypeus & Scarlet red & Blackish-brown & Brown \\
\hline Frons & Scarlet red & Crest yellow & Yellow \\
\hline Vesicles & Scarlet red & Yellow & Yellow \\
\hline Eyes above & Brown & Reddish brown & Dark brown \\
\hline Eyes below & Bright scarlet & Olivaceous & Olivaceous \\
\hline \multicolumn{4}{|l|}{ Thorax } \\
\hline Prothorax & Reddish-brown without any markings. & $\begin{array}{l}\text { Dark brown with citron yellow mid dorsal } \\
\text { stripe. }\end{array}$ & Brown with citron yellow mid dorsal stripe. \\
\hline Meta- and Mesothorax & Reddish-brown without any markings. & $\begin{array}{l}\text { Golden brown laterally, blackish-brown } \\
\text { dorsally with a bright yellow citron stripe. }\end{array}$ & $\begin{array}{l}\text { Brown laterally and dorsally with a bright } \\
\text { yellow citron stripe. }\end{array}$ \\
\hline \multicolumn{4}{|l|}{ Abdomen } \\
\hline Abdomen & Brilliant scarlet red. & $\begin{array}{l}\text { Dark golden brown, with a bright light yellow } \\
\text { strip on mid dorsum of segments 1-4. }\end{array}$ & $\begin{array}{l}\text { Golden brown, with a bright light yellow } \\
\text { strip on mid dorsum of segments 1-4. }\end{array}$ \\
\hline Coxites & Red, projecting and rounded at apex. & Absent & Brown, projecting and rounded at apex. \\
\hline $\begin{array}{l}\text { Secondary copulatory } \\
\text { apparatus }\end{array}$ & Present & Absent & Present (Image 2a,c) \\
\hline Lamina & Brownish-red, depressed arched. & & Golden brown, depressed arched. \\
\hline Hamules & $\begin{array}{l}\text { Bright red, small with a narrow base and } \\
\text { angled out. }\end{array}$ & & $\begin{array}{l}\text { Golden brown, small with a narrow base } \\
\text { and angled out. }\end{array}$ \\
\hline Hooks & Red, straight, projecting out. & & Golden brown, straight, projecting out. \\
\hline Penis vesicle & Bright red narrow and rounded. & & Golden brown, narrow and rounded. \\
\hline Penis & Dark red with a black tip. & & Brown with a black tip. \\
\hline \multicolumn{4}{|l|}{ Anal Appendages } \\
\hline Supra anal appendages & $\begin{array}{l}\text { Brilliant scarlet red, long, straight and spiny } \\
\text { beneath. }\end{array}$ & Brownish yellow, short conical. & $\begin{array}{l}\text { Golden yellow, long, straight and spiny } \\
\text { beneath (Image } 2 \mathrm{~b} \text { ). }\end{array}$ \\
\hline Infra anal appendage & Brilliant scarlet red, short obtuse at apex. & Absent & $\begin{array}{l}\text { Golden yellow, short obtuse at apex (Image } \\
2 \text { b). }\end{array}$ \\
\hline
\end{tabular}

indicates the possibility that the observed specimen is a gynochromatic male although it being a case of a reproductively active subadult male yet to acquire its adult "male" colour cannot be ruled out.

\section{REFERENCES}

Andrew, R.J. (2013). Andromorphic female of the dragonfly, Neurothemis tullia tullia (Drury) (Odonata: Libellulidae). Journa of Threatened Taxa 5(1): 3571-3573; http://dx.doi.org/10.11609/ JoTT.03143.155

Andrew, R.J., K.A. Subramanian \& A.D. Tiple (2008). A Handbook of Common Odonates of Central India. Published by the South Asian Council of Odonatology (SACO), India, during the 18th International Symposium of Odonatology" (ISSN- 978-81-910409-1-3), 54pp.

Corbet, P.S. (1999). Dragonflies: Behaviour and Ecology of Odonata. Harley Books, Colchester, England, 829pp.

Fraser, F.C. (1936). The Fauna of British India, including Ceylon and Burma. Odonata, Vol. III. Taylor and Francis, London, 461pp.

Fincke, O.M. (1992). Consequences of larval ecology for territoriality and reproductive success of a neotropical damselfly. Ecology 73 :
449-462.

Hinnekint, B.O.N. (1987). Population dynamics of Ischnura e. elegans (Vander Linden) (Insecta: Odonata) with special reference to morphological colour changes, female polymorphism, multiannual cycles and their influence on behavior. Hydrobiologia 146: 3-3; http://dx.doi.org/ 10.1007/BF00007574

McVey, M.E. (1985). Rates of colour maturation in relation to age, diet and temperature in male Erythemis simplicicollis (Say) (Anisoptera: Libellulidae). Odonatologica 14: 101-114.

Midttun, B. (1974). The anatomy of the male internal organ of reproduction in Somatochlora arctica (Zetterstedt) (Odonata: Corduliidae). Norwegian Journal of Zoology 24: 175-183.

Pajunen, V. I. (1962). Studies on the population ecology of Leucorrhinia dubia. V. d. Lind. (Odonata: Libellulidae). Annales Zoologici Societatis Zoologicae Fennicae 'Vanamo' 24(4): 1-79.

Subramanian, K.A. (2005). Dragonflies and Damselflies of Peninsular India; A Field Guide. Project Landscape, Indian Academy of Sciences, Bangalore, India, 118pp.

Uéda, T. (1989). Sexual maturation, body colour changes and increase of body weight in a summer diapauses population of the damselfly Lestes sponsa (Hansemann) (Zygoptera: Lestidae). Odonatologica 18: 75-87.

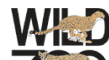

